\title{
What Should Clinicians Tell Patients about Placebo and Nocebo Effects? Practical Considerations Based on Expert Consensus
}

\author{
Andrea W.M. Evers ${ }^{a, b}$ Luana Colloca ${ }^{c}$ Charlotte Blease $^{d}$ Jens Gaab ${ }^{e}$ \\ Karin B. Jensen ${ }^{f}$ Lauren Y. Atlas ${ }^{g}$ Chris J. Beedie ${ }^{h} \quad$ Fabrizio Benedetti $^{i} \quad$ Ulrike Bingel ${ }^{j}$ \\ Christian Büchel $^{k}$ Jet Bussemaker ${ }^{l}$ Ben Colagiurim ${ }^{m}$ Alia J. Crum ${ }^{n}$ Damien G. Finniss ${ }^{\circ}$ \\ Andrew L. Geers ${ }^{p}$ Jeremy Howick ${ }^{q}$ Regine Klinger ${ }^{r}$ Stefanie H. Meeuwis ${ }^{a}$ \\ Karin Meissner $^{\mathrm{s}}$ Vitaly Napadow $^{\mathrm{t}}$ Keith J. Petrie $^{\mathrm{u}}$ Winfried Rief $^{\mathrm{v}}$ Ionica Smeets ${ }^{\mathrm{w}}$ \\ Tor D. Wager ${ }^{X}$ Vishvarani Wanigasekera ${ }^{y}$ Lene Vase $^{z}$ John M. Kelley ${ }^{A}$ \\ Irving Kirsch ${ }^{A}$ on behalf of the Consortium of Placebo Experts
}

\begin{abstract}
${ }^{a}$ Health, Medical and Neuropsychology Unit, Institute of Psychology, Leiden University, Leiden , The Netherlands; ${ }^{b}$ Erasmus University Rotterdam \& Delft University of Technology, Rotterdam/Delft, The Netherlands; ${ }^{c}$ Departments of Pain Translational Symptoms Science and Anesthesiology, School of Nursing and Medicine, University of Maryland Baltimore, Baltimore, MD, USA; ${ }^{\mathrm{d} G e n e r a l ~ M e d i c i n e ~ a n d ~ P r i m a r y ~ C a r e, ~ B e t h ~ I s r a e l ~ D e a c o n e s s ~ M e d i c a l ~}$

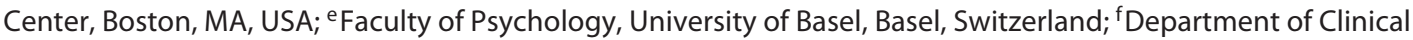
Neuroscience, Karolinska Institute, Stockholm, Sweden; ${ }^{9}$ National Center for Complementary and Integrative Health, National Institute of Mental Health, and National Institute on Drug Abuse, National Institutes of Health, Bethesda, MD, USA; ${ }^{h}$ School of Psychology, University of Kent, Canterbury, UK; 'Physiology and Neuroscience, University of Turin Medical School, Turin, Italy; 'Department of Neurology, University Hospital Essen, Essen, Germany; ${ }^{\text {Department }}$ of Systems Neuroscience, University Medical Center Hamburg-Eppendorf, Hamburg, Germany; 'Public Health and Primary Care, Leiden University Medical Center, Leiden, The Netherlands; ${ }^{\mathrm{m}}$ School of Psychology, University of Sydney, Sydney, NSW, Australia; ' Department of Psychology, Stanford University,

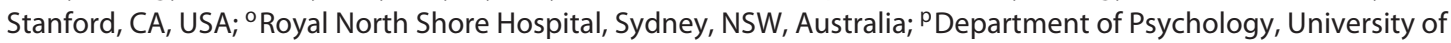
Toledo, Toledo, OH, USA; a Nuffield Department of Primary Care Health Sciences, University of Oxford, Oxford, UK; 'Center for Anesthesiology and Intensive Care Medicine, University Medical Center Hamburg-Eppendorf, Hamburg, Germany; ${ }^{\mathrm{s}}$ Division of Health Promotion, University of Applied Sciences, Coburg, Germany; ${ }^{\mathrm{t}}$ Athinoula A. Martinos Center for Biomedical Imaging, Charlestown, MA, USA; ${ }^{\text {u} D e p a r t m e n t ~ o f ~ P s y c h o l o g i c a l ~ M e d i c i n e, ~ U n i v e r s i t y ~ o f ~}$ Auckland, Auckland, New Zealand; ${ }^{v}$ Department of Clinical Psychology and Psychotherapy, Philipps University

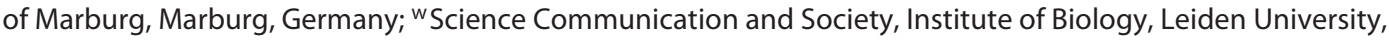
Leiden, The Netherlands; ${ }^{x}$ Department of Psychological and Brain Sciences, Dartmouth College, Hanover, NH, USA; y Nuffield Department of Clinical Neurosciences, University of Oxford, Oxford, UK; ${ }^{2}$ Department of Psychology and Behavioural Sciences, Aarhus University, Aarhus, Denmark; ${ }^{A}$ Beth Israel Deaconess Medical Center, Harvard Medical School, Program in Placebo Studies, Boston, MA, USA
\end{abstract}

\section{Keywords}

Placebo effects · Nocebo effects · Disclosure ·

Patient-clinician communication · Expert consensus

\begin{abstract}
Introduction: Clinical and laboratory studies demonstrate that placebo and nocebo effects influence various symptoms and conditions after the administration of both inert and active treatments. Objective: There is an increasing
\end{abstract}

(C) 2020 The Author(s)

Published by S. Karger AG, Basel

This is an Open Access article licensed under the Creative Commons Attribution-NonCommercial-4.0 International License (CC BY-NC) (http://www.karger.com/Services/OpenAccessLicense), applicable to the online version of the article only. Usage and distribution for commercial purposes requires written permission.
Andrea W.M. Evers

Health, Medical and Neuropsychology Unit, Institute of Psychology, Leiden University Wassenaarseweg 52, PO Box 9555

NL-2300 RB Leiden (The Netherlands)

a.evers@fsw.leidenuniv.nl 
need for up-to-date recommendations on how to inform patients about placebo and nocebo effects in clinical practice and train clinicians how to disclose this information. Methods: Based on previous clinical recommendations concerning placebo and nocebo effects, a 3-step, invitation-only Delphi study was conducted among an interdisciplinary group of internationally recognized experts. The study consisted of open- and closed-ended survey questions followed by a final expert meeting. The surveys were subdivided into 3 parts: (1) informing patients about placebo effects, (2) informing patients about nocebo effects, and (3) training clinicians how to communicate this information to the patients. Results: There was consensus that communicating general information about placebo and nocebo effects to patients (e.g., explaining their role in treatment) could be beneficial, but that such information needs to be adjusted to match the specific clinical context (e.g., condition and treatment). Experts also agreed that training clinicians to communicate about placebo and nocebo effects should be a regular and integrated part of medical education that makes use of multiple formats, including face-to-face and online modalities. Conclusions: The current 3-step Delphi study provides consensusbased recommendations and practical considerations for disclosures about placebo and nocebo effects in clinical practice. Future research is needed on how to optimally tailor information to specific clinical conditions and patients' needs, and on developing standardized disclosure training modules for clinicians.

(c) 2020 The Author(s)

Published by S. Karger AG, Basel

\section{Introduction}

Placebo and nocebo effects can substantially modulate the efficacy and tolerability of medical and psychological interventions for many symptoms and conditions [1-3]. Placebo and nocebo effects refer to favorable or adverse effects, respectively, that can arise as part of an active or inert intervention due to factors such as what the patient expects, the patient-clinician relationship, and other contextual factors [4-9]. These effects can be clinically meaningful, with effect sizes for some conditions approaching treatment effect sizes [10]. Placebo effects can be shaped by a wide range of factors relating to medical practice, e.g., verbal suggestions made by the clinician, nonverbal cues in the patient-clinician interaction, or situational factors in the health care environment [11-16]. Differing viewpoints as to how these effects should be handled exist, e.g., they are often seen as a nuisance in randomized controlled trials as they complicate the testing of new drugs and therapies $[17,18]$. On the other hand, there are potential benefits of utilizing placebo effects to boost treatment effects in clinical practice that have been recognized $[16,19,20]$, although there is a variety of proposed approaches. Moreover, some caution in utilizing the mechanisms of placebo effects in clinical practice may be prudent, as unforeseen adverse consequences (e.g., violation of expectation and loss of trust) may occur when effects are inadequately explained or elicited by deception (e.g., [21-23]).

Due to these controversies, only a few ideas have been generated on how knowledge about placebo and nocebo effects should be translated into clinical practice [20]. For example, there are not many national guidelines about the use of placebo effects in medical practice [8], and they typically do not provide concrete clinical recommendations on how to optimize care by maximizing placebo and minimizing nocebo effects in clinical practice $[24,25]$. It is also important to clearly distinguish between the deceptive use of inactive placebo treatments in clinical practice, which is not recommended, and the systematic use of the mechanisms underlying placebo and nocebo effects to enhance standard treatments in an open way. When considering the potentially wide application of placebo and nocebo effects across health care, there is a need for recommendations on how to communicate about them (e.g., during patient-clinician interactions) to optimize patient outcomes.

As a preliminary step, we provided consensus on the use of placebo and nocebo effects in clinical practice as part of the first official conference of the Society for Interdisciplinary Placebo Studies (SIPS) (https://www.placebosociety.org) [20]. This paper describes a follow-up to the previous recommendations [20] by collecting expert opinion on what should be communicated to patients about placebo and nocebo effects, and how clinicians should be trained to communicate about these topics in the context of medical patient-clinician interactions.

\section{Materials and Methods}

A modified Delphi study was organized for a panel of interdisciplinary experts by invitation (i.e., the speakers invited to participate at the 2019 SIPS conference) [26-28].

\section{Expert Group}

Twenty-seven internationally recognized and interprofessional placebo researchers took part in the panel, $67 \%$ of whom worked clinically (39\% physicians, 56\% psychologists, and 5\% other, e.g., acupuncturists). Their backgrounds included anesthesiology, neurology, cognitive neuroscience, primary care, internal medicine,
Evers et al. 
Fig. 1. Schematic overview of the considerations and the content of information needed for informing patients about placebo and nocebo effects in clinical practice.
Delphi Parts A \& B:

Informing patients about placebo and nocebo effects

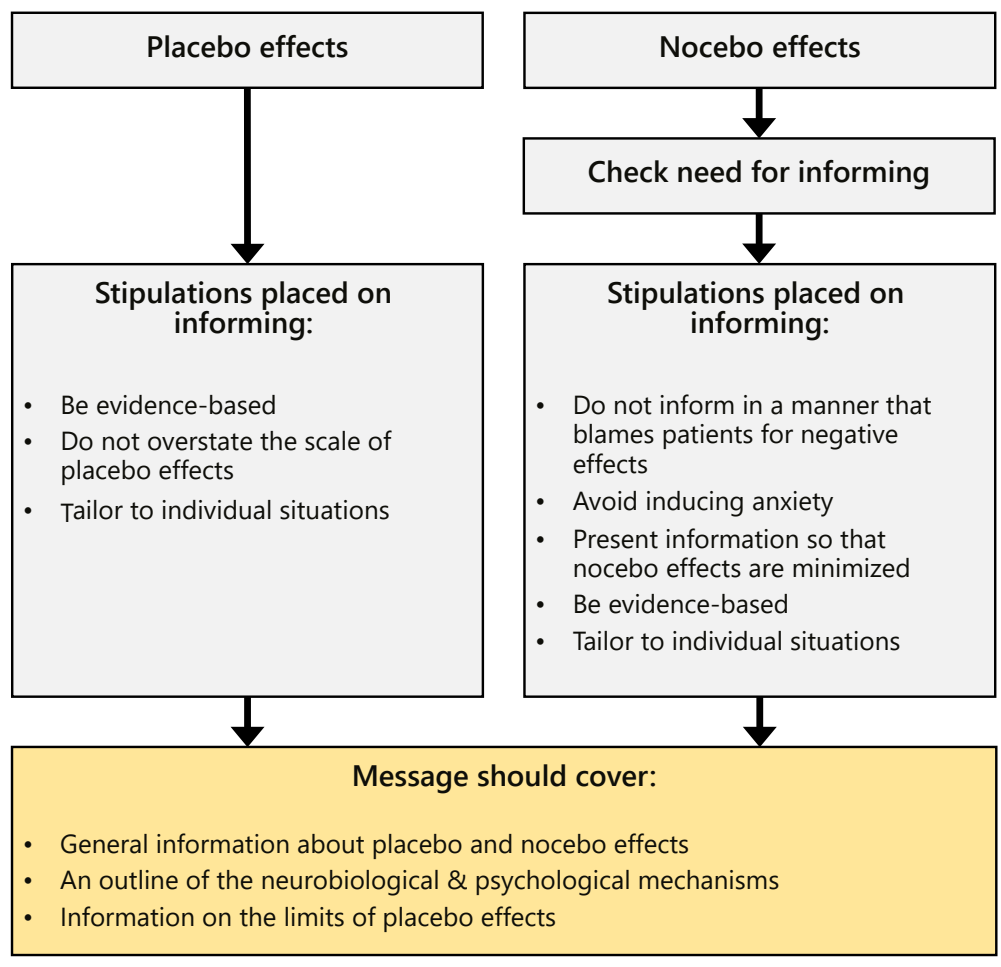

\section{Manner of informing:}

$\underline{\text { Terminology }}$

- Use 'placebo effects' (but explain carefully)

- Use 'nocebo effects' (but distinguish actual nocebo effects from adverse events)

- Adopt additional terminology to explain the mechanisms

Methodology:

- Not one method (information letter, consult, online information) is preferred over the other health and medical psychology, clinical psychology, psychological medicine, science communication, sports science, sociology, epidemiology, ethics, and philosophy.

\section{Modified Delphi Study}

Input for the Delphi study was derived from the existing literature [20]. An open-ended survey was used to generate content for expert consensus on informing patients about placebo and nocebo effects in clinical practice (e.g., what, when, and how should we communicate about these effects?), and how clinicians should be trained to communicate about placebo and nocebo effects. Answers were transcribed verbatim and aggregated into 158 individual items ranked on a scale of $0-10(0=$ totally disagree; $10=$ totally agree) in round 2 . Means and SD were calculated for each item. During round 3 (a preconference face-to-face clinical expert

Disclosure about Placebo and Nocebo Effects in Clinical Practice meeting, added to facilitate a nuanced discussion of possibly differing opinions on survey items), items with high agreement were discussed as input for the recommendations. More details on the methods used can be found in the online supplementary Material (see www.karger.com/doi/10.1159/000510738 for all online suppl. material).

\section{Results}

In the sections below and in Figure 1, we briefly describe the results of the Delphi study. The main recommendations are listed in Table 1. 
Table 1. Main recommendations formulated by the expert group for communicating information about placebo and nocebo effects

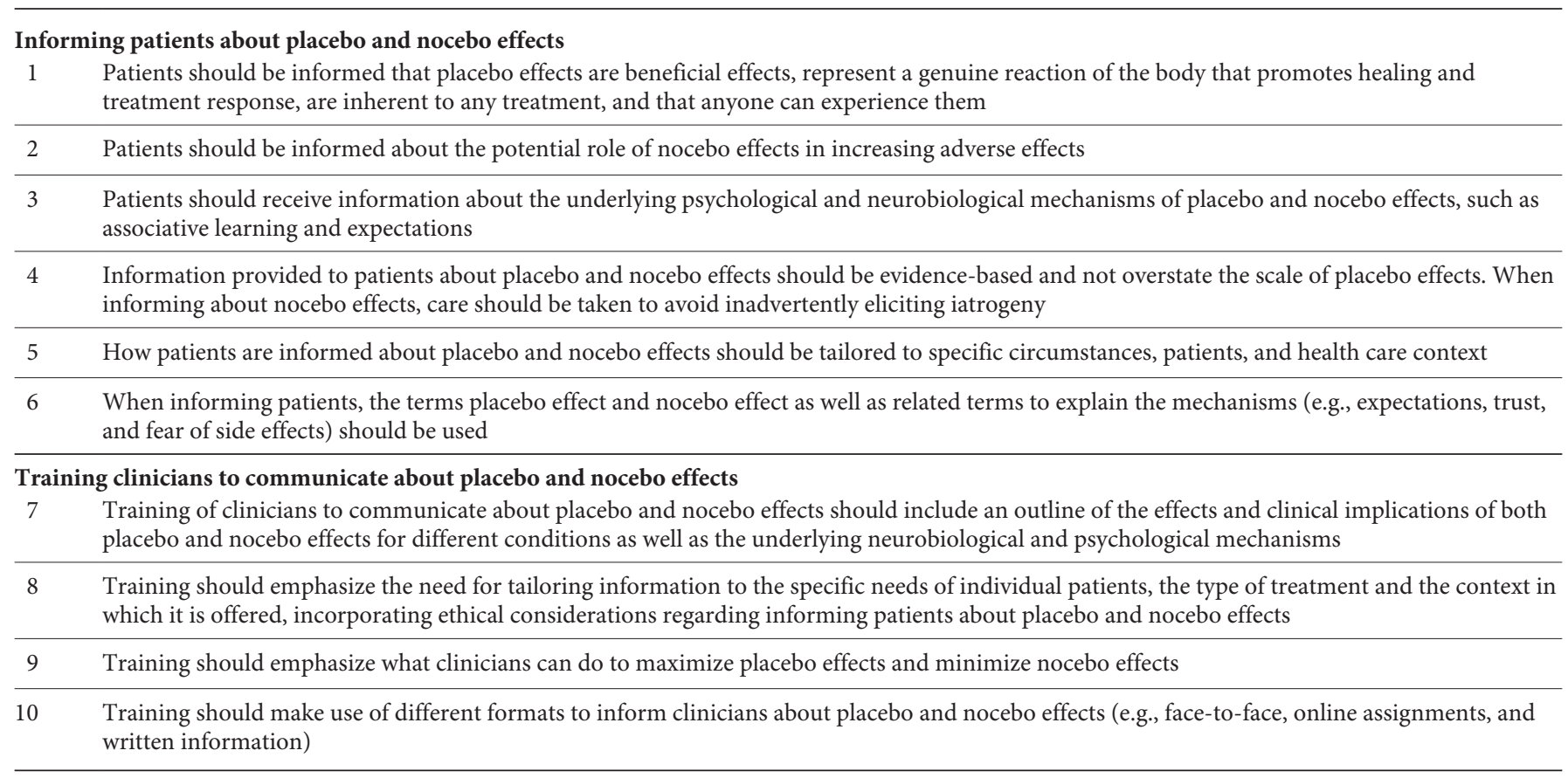

Informing Patients about Placebo and Nocebo Effects

Based on the broad evidence for placebo and nocebo effects in clinical, neurobiological, and laboratory outcomes $[5-7,19,22,29-39]$, the experts agreed that placebo and nocebo effects should be explained, and that patients should receive at least general information about these effects. Providing an outline of the neurobiological and psychological mechanisms could also be helpful, as could informing patients about the limits of placebo effects (e.g., placebo effects are likely to affect symptoms but not the progression of a disease) [40]. The experts recommended placing several stipulations on informing patients about placebo and nocebo effects, e.g., information must be evidence-based and should not overstate the size of placebo effects. For both placebo and nocebo effects, the experts agreed that the information should be tailored to specific patients, conditions, and circumstances. For nocebo effects, this need was particularly emphasized, as a consequence of a delicate balance between following the ethics guidelines of informed consent (according to which patients need to be fully informed about risks and side effects of treatments as well as the possibility of treatment failures) and simultaneously preventing and reducing nocebo effects as much as possible [40-42]. Moreover, for nocebo effects, the need for informing should be considered, and, when deemed necessary, such disclosures should be made carefully in a manner that does not increase anxiety and is not perceived as blaming patients for negative treatment effects (i.e., side effects). Information should, moreover, be presented in a way that minimizes nocebo effects.

Regarding terminology, it was agreed that using the terms "placebo effect" and "nocebo effect" is acceptable, provided they are explained carefully, and that actual nocebo effects be distinguished from adverse events. When explaining the mechanisms involved, or if information is difficult for a patient to understand, clinicians may consider using slightly different terminology (e.g., classical conditioning or response expectancy). Regarding the manner of informing, no one method (information leaflet, consultation, or online information) was preferred over the others.

\section{Training Clinicians in Communicating about Placebo} and Nocebo Effects

Next to substantive information about placebo and nocebo effects (e.g., mechanisms, neurobiological and physiological underpinnings, variations in effect sizes and duration of effects, and that placebo effects can also work when people know about the effect), the experts agreed that clinicians should be taught about the relevant ethical issues concerning placebo and nocebo effects. 
Training could, moreover, emphasize that different patients might require different information, and that placebo and nocebo effects can operate differently for different conditions. Finally, an emphasis should be placed on what clinicians can do to maximize placebo effects and minimize nocebo effects (i.e., deploying strategies such as optimizing verbal and nonverbal communication [15, 30-33, 43-52]).

As to the content of training, the experts agreed that it may be useful to use both general modules as well as modules relevant to specific medical conditions or specialists. They agreed that medical ethics education regarding placebo and nocebo effects should be a routine part of clinical training. Training should preferably be embedded in a medical school or other standard education. However, the experts concluded during the meeting that more research is needed and that empirical testing of the efficacy of training methods is essential.

More details on the Delphi results can be found in the online supplementary Material.

\section{Discussion}

This paper supplies the most up-to-date consensusbased recommendation for communicating information about placebo and nocebo effects in clinical practice (Table 1). The recommendations can support clinicians in their communications with their patients about placebo and nocebo effects.

The results reflect several established and emerging strands of literature in this area. For example, the need to communicate about side effects in ways that do not induce nocebo effects is gaining more widespread recognition [30, 32, 53-58]. Because of ethical considerations $[40,41]$, tailoring information seems to be particularly imperative for nocebo effects, especially for those patients who may have a high risk of developing these effects [30$32,43,53,59]$. The consensus on communicating information about mechanisms is also reflected in studies showing that understanding the mechanisms of placebo effects may help to maximize these effects in clinical practice $[2,20,42,60-62]$.

The results showed a relatively high agreement among the experts that patients should receive general information about placebo and nocebo effects. This includes consensus that the inherent role of these effects in any treatment should be explained, as should related mechanisms like the patient-clinician relationship, but also that this information needs to be adjusted to the specific context

Disclosure about Placebo and Nocebo Effects in Clinical Practice (e.g., the characteristics of the patients, the condition in question, and the treatment). For the latter recommendation, the need for careful consideration by the clinician on when and how to communicate information about placebo and nocebo effects should be recognized. This need is partly reflected in the consensus that, for instance, information should be evidence-based and presented without overstating the scale of placebo effects. Overselling placebo effects may cause a violation of expectations when these are too high, thereby eroding trust in health care professionals, which, in turn, may lead to other negative consequences such as disengagement/nonadherence with care (e.g., [21-23]). It is important to emphasize that placebo effects can help optimize treatment outcomes but that they cannot cure disease.

Moreover, clinicians may want to appraise what information is appropriate for each individual patient, and exercise restraint when the benefit of supplying information to a patient is questionable. Care should be taken to not inadvertently elicit iatrogeny, i.e., unintended negative outcomes due to treatment [63-65]. This is a complex issue, where a difficult balance exists between having to inform a patient of the potential side effects of treatment and not causing too much alarm [65]. When done appropriately, informing patients about placebo and nocebo effects may help enhance naturally occurring placebo effects in clinical practice and can even boost the efficacy of a treatment while simultaneously reducing nocebo effects.

The Delphi method has several advantages: it offers rapid consensus and a wide range of expertise can be included, while a socially desirable response due to group pressure is minimized. However, the methodology is not without limitations [26-28]. For example, the biases of the group (who all focus on studying placebos) may have influenced item selection. Also, some panel members may have been more outspoken than others during group discussions. It was nevertheless possible to reach consensus regarding the main recommendations for informing patients and training health professionals.

The recommendations may not encompass all nuances that are typically found in placebo research. For example, it is recommended that general mechanisms are explained, but no recommendations are provided about interactions of these mechanisms with other treatment factors. Another limitation is that some topics may have been overlooked. Additionally, these guidelines may not be generalizable to nonmedical contexts, such as physical therapy, psychotherapy, or treatments for which the role of placebo and nocebo effects has not yet been illustrated. 
It should also be noted that the recommendations do not legitimize any form of nonevidence-based treatment, nor are we suggesting that proven therapies should be replaced with placebo treatments $[66,67]$. Our method also did not allow us to draw conclusions about specific strategies that can maximize placebo effects and minimize nocebo effects for a range of different conditions and contexts. Although we acknowledge their likely importance, we also did not focus on sociodemographic, cultural, personality, or genetic differences between patients in view of the limited existing evidence for subgroups of placebo and nocebo responders [68-70]. For example, there is emerging evidence that specific genotypes (e.g., $[5,71-$ 73]) may be associated with variation in the scale of placebo and nocebo effects, but there is not yet enough evidence to include these findings in clinical recommendations.

Methodologically well-conducted replication studies that support the external validity of our findings are needed for all these areas. Finally, the consensus described here should only be seen as hypothesis-generating. As a consequence, the experts emphasized the need for research focusing on tailoring information to different patients and contexts, and developing evidence-based methods for training clinicians to communicate about placebo and nocebo effects.

This study, based on a 3-stage Delphi approach, is an important step forward towards consensus-based recommendations for communicating about placebo and nocebo effects in medical practice. The experts agreed that patients should receive general information about the mechanisms and neurobiology of placebo and nocebo effects, but that care should be taken to adjust this information to the specific needs of patients and the treatment context. Multimodal training in communication about placebo and nocebo effects should be a regular and integrated part of medical training for clinicians. The experts acknowledged the need for future research to expand knowledge about how best to provide information to patients, and about how clinicians can communicate about placebo and nocebo effects in the course of a treatment.
Finally, implementation strategies should be developed to integrate these recommendations into clinical practice and the routine training and education of clinicians.

\section{Acknowledgement}

We would like to acknowledge the following colleagues of the local organizing team of the SIPS conference for their support in the preparation of the survey and meeting described in this paper: KJ Peerdeman, A Skvortsova, L van Vliet, DS Veldhuijzen, JAB Mink, and AE Breugem.

\section{Statement of Ethics}

Ethics approval was not required.

\section{Conflict of Interest Statement}

The authors have no conflicts of interest to declare.

\section{Funding Sources}

This report was supported by an ERC Consolidator grant (ERC-2013-CoG 617700 EXPECT HEAL-TH), an NWO Vici grant (No. 45316004), and an NWO Stevin prize, all granted to A.W.M.E. L.Y.A. is supported in part by the Intramural Research Program of the National Center for Complementary and Integrative Health. U.B., W.R., and R.K. were funded by the Deutsche Forschungsgemeinschaft (project ID 422744262-TRR 289). The funders had no role in the acquisition or analysis of the data or the content of this article.

\section{Author Contributions}

A workgroup of the SIPS local organizers and international board members (A.W.M.E., L.C., J.G., K.B.J., J.K., L.V., C.J.B., I.K., and S.H.M.) prepared the initiative for the Delphi survey. A.W.M.E. and S.H.M., together with the other work group members, prepared and analyzed the results of the first and second Delphi surveys, prepared the expert meeting, and wrote the paper. All authors contributed to the Delphi survey and/or expert meeting and provided feedback on drafts of the manuscript.

\section{References}

1 Damien J, Colloca L, Bellei-Rodriguez CE, Marchand S. Pain modulation: from conditioned pain modulation to placebo and nocebo effects in experimental and clinical pain. Int Rev Neurobiol. 2018;139:255-96.

2 Petrie KJ, Rief W. Psychobiological mechanisms of placebo and nocebo effects: path- ways to improve treatments and reduce side effects. Annu Rev Psychol. 2019 Jan;70(1): 599-625.

3 Tekampe J, van Middendorp H, Meeuwis SH, van Leusden JW, Pacheco-López G, Hermus AR, et al. Conditioning immune and endocrine parameters in humans: a systematic review. Psychother Psychosom. 2017;86(2): 99-107.

4 Chavarria V, Vian J, Pereira C, Data-Franco J, Fernandes BS, Berk M, et al. The placebo and nocebo phenomena: their clinical management and impact on treatment outcomes. Clin Ther. 2017 Mar;39(3):477-86. 
5 Colagiuri B, Schenk LA, Kessler MD, Dorsey SG, Colloca L. The placebo effect: from concepts to genes. Neuroscience. 2015 Oct;307: 171-90.

6 Kaptchuk TJ, Miller FG. Placebo effects in medicine. N Engl J Med. 2015 Jul;373(1):8-9.

7 Wager TD, Atlas LY. The neuroscience of placebo effects: connecting context, learning and health. Nat Rev Neurosci. 2015 Jul;16(7):40318.

8 Colloca L, Barsky AJ. Placebo and nocebo effects. N Engl J Med. 2020 Feb;382(6):554-61.

9 Schmitz J, Müller M, Stork J, Eichler I, Zöllner $\mathrm{C}$, Flor $\mathrm{H}$, et al. Positive treatment expectancies reduce clinical pain and perceived limitations in movement ability despite increased experimental pain: a randomized controlled trial on sham opioid infusion in patients with chronic back pain. Psychother Psychosom. 2019;88(4):203-14.

10 Wampold BE, Minami T, Tierney SC, Baskin TW, Bhati KS. The placebo is powerful: estimating placebo effects in medicine and psychotherapy from randomized clinical trials. J Clin Psychol. 2005 Jul;61(7):835-54.

11 Blasini M, Peiris N, Wright T, Colloca L. The role of patient-practitioner relationships in placebo and nocebo phenomena. Int Rev Neurobiol. 2018;139:211-31.

12 Kleine-Borgmann J, Bingel U. Nocebo effects: neurobiological mechanisms and strategies for prevention and optimizing treatment. Int Rev Neurobiol. 2018;138:271-83.

13 Meissner K, Linde K. Are blue pills better than green? How treatment features modulate placebo effects. Int Rev Neurobiol. 2018;139: 357-78.

14 Necka EA, Atlas LY. The role of social and interpersonal factors in placebo analgesia. Int Rev Neurobiol. 2018;138:161-79.

15 Rossettini G, Carlino E, Testa M. Clinical relevance of contextual factors as triggers of placebo and nocebo effects in musculoskeletal pain. BMC Musculoskelet Disord. 2018 Jan;19(1):27.

16 Zion SR, Crum AJ. Mindsets matter: a new framework for harnessing the placebo effect in modern medicine. Int Rev Neurobiol. 2018; 138:137-60.

17 Friesen P. Mesmer, the placebo effect, and the efficacy paradox: lessons for evidence-based medicine and complementary and alternative medicine. Crit Public Health. 2019;29(4): 435-47.

18 Vase L, Wartolowska K. Pain, placebo, and test of treatment efficacy: a narrative review. Br J Anaesth. 2019 Aug;123(2):e254-62.

19 Enck P, Bingel U, Schedlowski M, Rief W. The placebo response in medicine: minimize, maximize or personalize? Nat Rev Drug Discov. 2013 Mar;12(3):191-204.

20 Evers AW, Colloca L, Blease C, Annoni M, Atlas LY, Benedetti F, et al. Implications of placebo and nocebo effects for clinical practice: expert consensus. Psychother Psychosom. 2018;87(4):204-10.

21 Colloca L, Schenk LA, Nathan DE, Robinson OJ, Grillon C. When expectancies are violat- ed: a functional magnetic resonance imaging study. Clin Pharmacol Ther. 2019 Dec;106(6): 1246-52.

22 Fava GA, Guidi J, Rafanelli C, Rickels K. The clinical inadequacy of the placebo model and the development of an alternative conceptual framework. Psychother Psychosom. 2017; 86(6):332-40.

23 Annoni M, Miller FG. Informed consent and the ethics of placebo-based interventions for migraine in clinical practice. Placebo and nocebo in headache. London, Berlin: Springer; 2019.

24 American Medical Association [Internet] Use of placebo in clinical practice [cited 2019]. Available from: https://wwwama-assnorg/delivering-care/ethics/use-placeboclinical-practice.

25 der Bundesärztekammer. Placebo in der Medizin. Dtsch Arztebl. 2010;107:B1253-7.

26 Hasson F, Keeney S, McKenna H. Research guidelines for the Delphi survey technique. J Adv Nurs. 2000 Oct;32(4):1008-15.

27 Linstone HA. The Delphi method: techniques and applications. Reading: Adison Wesley; 1979.

28 McMillan SS, King M, Tully MP. How to use the nominal group and Delphi techniques. Int J Clin Pharm. 2016 Jun;38(3):655-62.

29 Benedetti F. Understanding the mechanisms in health and disease. Oxford: University Press Oxford; 2009.

30 Colloca L, Finniss D. Nocebo effects, patientclinician communication, and therapeutic outcomes. JAMA. 2012 Feb;307(6):567-8.

31 Evers AW. Using the placebo effect: how expectations and learned immune function can optimize dermatological treatments. Exp Dermatol. 2017 Jan;26(1):18-21.

32 Greville-Harris M, Dieppe P. Bad is more powerful than good: the nocebo response in medical consultations. Am J Med. 2015 Feb; 128(2):126-9.

33 Klinger R, Colloca L, Bingel U, Flor H. Placebo analgesia: clinical applications. Pain. 2014 Jun;155(6):1055-8.

34 Klinger R, Kothe R, Schmitz J, Kamping S, Flor H. Placebo effects of a sham opioid solution: a randomized controlled study in patients with chronic low back pain. Pain. 2017 Oct; 158(10):1893-902.

35 Peerdeman KJ, van Laarhoven AI, Keij SM, Vase L, Rovers MM, Peters ML, et al. Relieving patients' pain with expectation interventions: a meta-analysis. Pain. 2016 Jun;157(6): 1179-91.

36 Petersen GL, Finnerup NB, Colloca L, Amanzio M, Price DD, Jensen TS, et al. The magnitude of nocebo effects in pain: a meta-analysis. Pain. 2014 Aug;155(8):1426-34.

37 Schedlowski M, Enck P, Rief W, Bingel U. Neuro-bio-behavioral mechanisms of placebo and nocebo responses: implications for clinical trials and clinical practice. Pharmacol Rev. 2015 Jul;67(3):697-730.

38 Wolters F, Peerdeman KJ, Evers AW. Placebo and nocebo effects across symptoms: from pain to fatigue, dyspnea, nausea and itch. Front Psychiatry. 2019 Jul;10:470.

39 Colloca L, Akintola T, Haycock NR, Blasini M, Thomas S, Phillips J, et al. Prior therapeutic experiences, not expectation ratings, predict placebo effects: an experimental study in chronic pain and healthy participants. Psychother Psychosom. 2020. Doi: 10.1159/ 000507400 .

40 Friesen P. Placebos as a source of agency: evidence and implications. Front Psychiatry. 2019 Oct; $10: 721$.

41 Alfano M. Placebo effects and informed consent. Am J Bioeth. 2015;15(10):3-12.

42 Manaï $M$, van Middendorp $H$, Veldhuijzen DS, Huizinga TW, Evers AW. How to prevent, minimize, or extinguish nocebo effects in pain: a narrative review on mechanisms, predictors, and interventions. Pain Rep. 2019 Jun;4(3):e699.

43 Charlesworth JE, Petkovic G, Kelley JM, Hunter M, Onakpoya I, Roberts N, et al. Effects of placebos without deception compared with no treatment: A systematic review and meta-analysis. J Evid Based Med. 2017 May; 10(2):97-107.

44 Colloca L. Tell me the truth and I will not be harmed: informed consents and nocebo effects. Am J Bioeth. 2017 Jun;17(6):46-8.

45 Colloca L, Howick J. Placebos without deception: outcomes, mechanisms, and ethics. Int Rev Neurobiol. 2018;138:219-40.

46 Daniali H, Flaten MA. A qualitative systematic review of effects of provider characteristics and nonverbal behavior on pain, and placebo and nocebo effects. Front Psychiatry. 2019 Apr; 10:242.

47 Howe LC, Leibowitz KA, Crum AJ. When your doctor "gets it" and "gets you": the critical role of competence and warmth in the patient-provider interaction. Front Psychiatry. 2019 Jul; 10:475.

48 Howick J, Moscrop A, Mebius A, Fanshawe TR, Lewith G, Bishop FL, et al. Effects of empathic and positive communication in healthcare consultations: a systematic review and meta-analysis. J R Soc Med. 2018 Jul;111(7): 240-52.

49 Kelley JM, Kaptchuk TJ, Cusin C, Lipkin S, Fava M. Open-label placebo for major depressive disorder: a pilot randomized controlled trial. Psychother Psychosom. 2012;81(5):312-4.

50 Locher C, Frey Nascimento A, Kirsch I, Kossowsky J, Meyer A, Gaab J. Is the rationale more important than deception? A randomized controlled trial of open-label placebo analgesia. Pain. 2017 Dec;158(12):2320-8.

51 Palese A, Rossettini G, Colloca L, Testa M. The impact of contextual factors on nursing outcomes and the role of placebo/nocebo effects: a discussion paper. Pain Rep. 2019 Jun; 4(3):e716.

52 Rossettini G, Palese A, Geri T, Fiorio M, Colloca L, Testa M. Physical therapists' perspectives on using contextual factors in clinical practice: findings from an Italian national survey. PLoS One. 2018 Nov;13(11):e0208159. 
53 Blease C. Authorized concealment and authorized deception: well-intended secrets are likely to induce nocebo effects. Am J Bioeth. 2015;15(10):23-5.

54 Crichton F, Petrie KJ. Health complaints and wind turbines: the efficacy of explaining the nocebo response to reduce symptom reporting. Environ Res. 2015 Jul;140:449-55.

55 Faasse K, Huynh A, Pearson S, Geers AL, Helfer SG, Colagiuri B. The influence of side effect information framing on nocebo effects. Ann Behav Med. 2019 Jun;53(7):621-9.

56 Heisig SR, Shedden-Mora MC, Hidalgo P, Nestoriuc Y. Framing and personalizing informed consent to prevent negative expectations: an experimental pilot study. Health Psychol. 2015 Oct;34(10):1033-7.

57 Howick J. Unethical informed consent caused by overlooking poorly measured nocebo effects. J Med Ethics. 2020. DOI: 10.1136/medethics-2019-105903.

58 Pouillon L, Danese S, Hart A, Fiorino G, Argollo M, Selmi C, et al. Consensus report: clinical recommendations for the prevention and management of the nocebo effect in biosimilar-treated IBD patients. Aliment Pharmacol Ther. 2019 May;49(9):1181-7.

59 Svensberg K, Nordeng H, Gaffari S, Faasse K, Horne R, Lupattelli A. Perceived sensitivity to medicines: a study among chronic medicine users in Norway. Int J Clin Pharm. 2019 Jun; 41(3):804-12.

60 Blease C. The principle of parity: the 'placebo effect' and physician communication. J Med Ethics. 2012 Apr;38(4):199-203.

61 Crum A, Zuckerman B. Changing mindsets to enhance treatment effectiveness. JAMA. 2017 May;317(20):2063-4.

62 Klinger R, Stuhlreyer J, Schwartz M, Schmitz J, Colloca L. Clinical use of placebo effects in patients with pain disorders. Int Rev Neurobiol. 2018;139:107-28.

63 Barsky AJ. The iatrogenic potential of the physician's words. JAMA. 2017 Dec;318(24): 2425-6.

64 Bootzin RR, Bailey ET. Understanding placebo, nocebo, and iatrogenic treatment effects. J Clin Psychol. 2005 Jul;61(7):871-80.

65 Fava GA, Rafanelli C. Iatrogenic factors in psychopathology. Psychother Psychosom. 2019;88(3):129-40.

66 Beedie C, Whyte G, Lane AM, Cohen E, Raglin J, Hurst P, et al. 'Caution, this treatment is a placebo. It might work, but it might not': why emerging mechanistic evidence for placebo effects does not legitimise complementary and alternative medicines in sport. $\mathrm{Br} \mathrm{J}$ Sports Med. 2018 Jul;52(13):817-8.

67 Benedetti F. The dangerous side of placebo research: is hard science boosting pseudosci- ence? Clin Pharmacol Ther. 2019 Dec;106(6): $1166-8$.

68 Friesen P, Blease C. Placebo effects and racial and ethnic health disparities: an unjust and underexplored connection. J Med Ethics. 2018 Nov;44(11):774-81.

69 Geers AL, Helfer SG, Kosbab K, Weiland PE, Landry SJ. Reconsidering the role of personality in placebo effects: dispositional optimism, situational expectations, and the placebo response. J Psychosom Res. 2005 Feb;58(2): 121-7.

70 Trivedi MH, South C, Jha MK, Rush AJ, Cao J, Kurian B, et al. A novel strategy to identify placebo responders: prediction index of clini$\mathrm{cal}$ and biological markers in the EMBARC trial. Psychother Psychosom. 2018;87(5): 285-95.

71 Colloca L, Wang Y, Martinez PE, Chang YC, Ryan KA, Hodgkinson C, et al. OPRM1 rs1799971, COMT rs4680, and FAAH rs324420 genes interact with placebo procedures to induce hypoalgesia. Pain. 2019 Aug; 160(8):1824-34.

72 Hall KT, Loscalzo J, Kaptchuk T. Pharmacogenomics and the placebo response. ACS Chem Neurosci. 2018 Apr;9(4):633-5.

73 Hall KT, Loscalzo J, Kaptchuk TJ. Genetics and the placebo effect: the placebome. Trends Mol Med. 2015 May;21(5):285-94. 